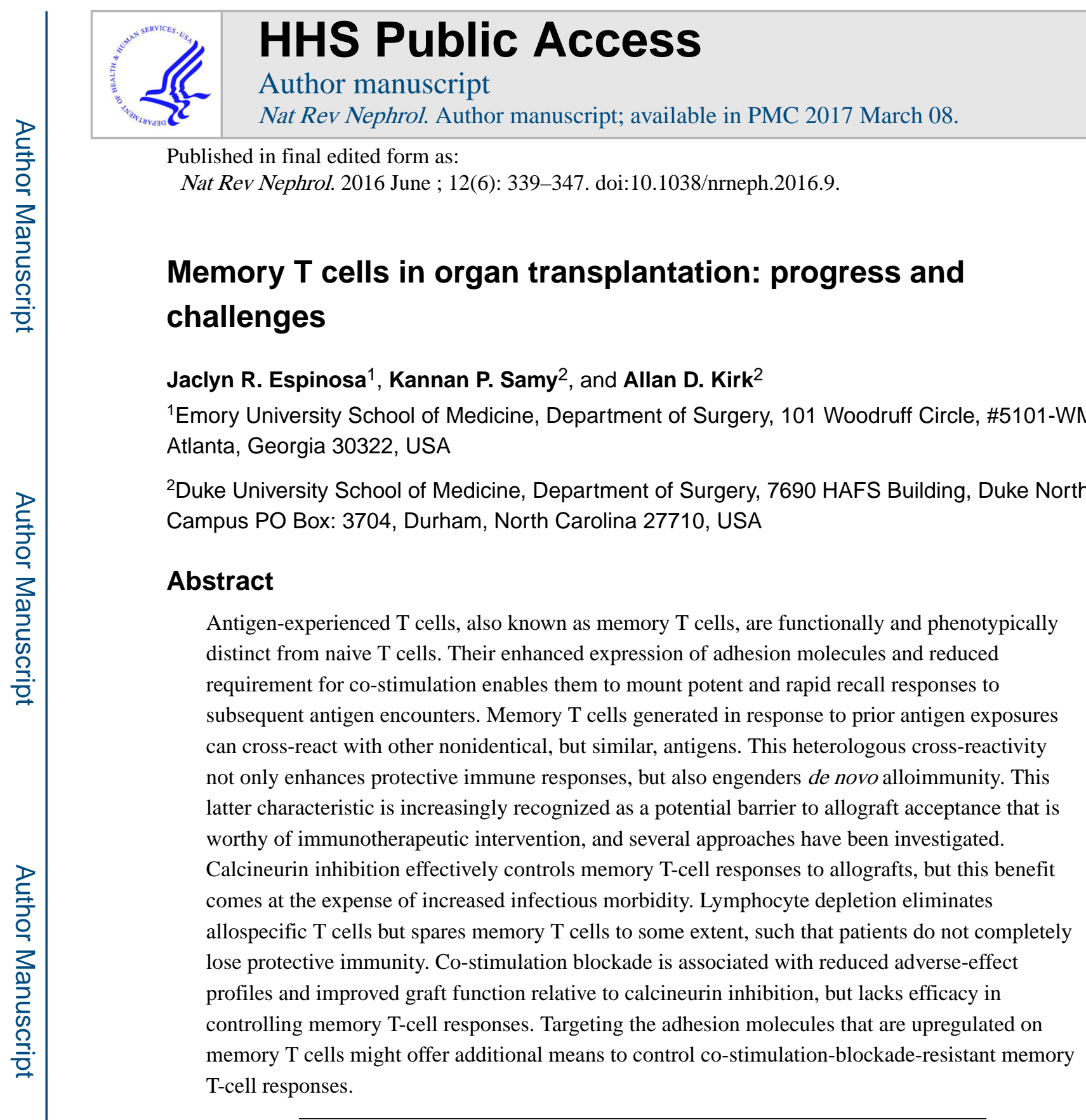

A defining hallmark of adaptive or acquired immunity is the ability to generate an anamnestic response ${ }^{1}$ - a heightened responsiveness to successive antigen encounters which forms the basis of long-term immunity. This response is largely attributed to memory $\mathrm{T}$ cells, which have long-lasting survival properties, strong effector responses and the ability to quickly become activated in the periphery.

Correspondence to A.D.K. allan.kirk@ duke.edu.

Author contributions

All authors researched the data, made substantial contributions to discussions of the content, wrote the article and reviewed and/or edited the manuscript before submission.

Competing interests statement

The authors declare no competing interests. 
Following the initial characterization of four memory T-cell subsets on the basis of surface expression of CCR7 and CD45RA ${ }^{2}$, it has become recognized that the surface phenotype of a memory $\mathrm{T}$ cell is associated with distinct functional capabilities. The increasing ability to investigate defined T-cell subsets and their responses to secondary antigen exposure has facilitated the elucidation of the complex plasticity of memory $\mathrm{T}$ cells; the four classically described subsets have expanded tremendously over time. This broad spectrum of antigenexperienced cells presents a major obstacle to the stable acceptance of transplanted organs; memory $\mathrm{T}$ cells are crucial mediators of allograft rejection ${ }^{3}$. In this Review, we describe the generation of memory $\mathrm{T}$ cells, the phenotypic markers associated with the best-defined subsets, their postulated impact on allograft rejection, and immune management strategies to mitigate their effects.

\section{Memory T cells}

Naive $\mathrm{T}$ cells have not encountered antigens in the periphery and require multiple stimuli to elicit an immune response. Antigen experience - defined as an interaction between a T-cell receptor (TCR) and its cognate antigen that is sufficient to induce T-cell differentiation alters numerous intracellular and extracellular properties. In a memory $\mathrm{T}$ cell, these changes generally improve the efficiency and robustness of the response to subsequent antigen encounters ${ }^{4}$. It is important to note, however, that other responses to an antigen can also drive distinct differentiation pathways with markedly different functional outcomes, such as T-cell exhaustion ${ }^{5}$, which lessens the capacity of a cell to carry out its effector functions. Thus, although all memory $\mathrm{T}$ cells derive from antigen experience, antigen experience does not necessarily lead to the production of memory $\mathrm{T}$ cells.

\section{Formation}

Two conceptual models for the development and maintenance of memory $\mathrm{T}$ cells have been proposed: sequential and parallel differentiation (FIG. 1). Both of these pathways of differentiation likely occur and considerable plasticity has been demonstrated.

Sequential differentiation-The concept of sequential differentiation proposes a stepwise paradigm for the formation of memory $\mathrm{T}$ cells (FIG. 1a). When a naive $\mathrm{T}$ cell interacts with its cognate antigen, it undergoes clonal expansion and acquires effector function before contracting to one of two memory phenotypes: central memory or effector memory (note that an effector cell is distinct from an effector memory cell) ${ }^{6,7}$. Effector memory and central memory $\mathrm{T}$ cells both persist after encountering a primary antigen, but differ in several respects. Central memory $\mathrm{T}$ cells move to secondary lymphoid organs, are long lived and maintain a high proliferative capacity, making them effective at amplifying secondary responses to subsequent antigen exposures. By contrast, effector memory $\mathrm{T}$ cells circulate in the periphery, are shorter lived, and have a relatively reduced proliferative capacity — thus, although they are superior in their ability to infiltrate areas of inflammation and exert their effector function, they are less suited to expansion ${ }^{8,9}$.

The linear model of progression from naive to effector to memory (central or effector) T cell proposes that the fate of a naive $\mathrm{T}$ cell following antigen stimulation is determined by the duration and affinity of the TCR engagement and the nature of the ambient cytokine 
milieu $^{2,10,11}$. Other studies using an acute infection model of lymphocytic choriomeningitis virus (LCMV) and LCMV-specific TCR transgenic mice suggest that effector memory T cells represent an intermediate phenotype in the transition from effector $\mathrm{T}$ cells to central memory T cells ${ }^{7,12}$.

Parallel differentiation-The concept of parallel differentiation proposes that following antigen engagement, an activated $\mathrm{T}$ cell divides to yield two daughter cells with distinct phenotypes and capabilities (FIG. 1b). Studies have shown that a single naive T cell can give rise to a diverse pool of effector and memory T cells ${ }^{13-15}$. Asymmetric T-cell division resulting from cell polarization has been observed in parent cells preparing to undergo their first round of cell division. Formation of the immunological synapse provides a method for stabilizing and prolonging the specific, high-affinity interaction between the TCR and the $\mathrm{MHC}^{16}$, and this persistent polarization can result in asymmetric segregation of cell-fate proteins during cell division, thereby enabling diverse T-cell progeny ${ }^{17}$. Antigen encounters or transient interactions driven by low-affinity TCR engagement, such as those that occur during homeostatic proliferation, do not result in polarization or asymmetric daughter cell division, supporting the idea that the immunological synapse coordinates asymmetric cell division and parallel differentiation ${ }^{18}$.

Plasticity-Additional studies tracking cell-cycle states have shown that a subset of CD8 ${ }^{+}$ $\mathrm{T}$ cells slow their cell cycle, reduce their proliferation and develop a central-memory-like phenotype following the initial burst of fast-cycling effector cell proliferation ${ }^{19}$. Thus, activated $\mathrm{T}$ cells seem to have the intrinsic ability to reprogram their cell cycle to initiate memory cell differentiation programs in parallel with the existence of a fast-cycling effector pool. The cytokine milieu available during an antigen encounter also affects this differentiation. For example, $\mathrm{CD}^{+} \mathrm{T}$ cells cultured in the presence of IL-2 form primary effector cells, whereas those cultured in the presence of IL-15 skew directly to memory cells that are able to mount a secondary immune response upon re-challenge ${ }^{20}$. These studies not only highlight the importance of environmental influences on T-cell differentiation, but also suggest that effector differentiation is not a prerequisite for memory generation.

The spectrum of affinities encountered during an alloimmune response is broad, ranging from low affinity, similar to that reported for exposure to autoantigens during homeostatic proliferation, to high affinity, approximating exposure to viral antigens ${ }^{21}$. As such, physiologic immune responses might distinguish between immune homeostasis and effector differentiation, whereas alloimmune responses might provide a spectrum of responses to a variety of antigen encounters.

The available data provide well-founded support for the existence of both sequential and parallel T-cell differentiation pathways; data to disprove either hypothesis is scarce. Taken as a whole, it is becoming appreciated that considerable plasticity in T-cell differentiation exists, with numerous maturation pathways between naive, effector and memory populations (FIG. 1c). These pathways are influenced by environmental cues and cell-cell interactions. Indeed, the fluidity of the immune system has likely been evolutionarily conserved to protect the host from the wide array of constantly evolving pathogens. These pathways to effector and memory differentiation also overlap with numerous programs for cell death, anergy, 
exhaustion and senescence, which will not be considered in this Review, but are equally necessary for a truly adaptive response to pathogens.

\section{Co-stimulation}

Naive $\mathrm{T}$ cells require numerous signals to enter a program of differentiation. This requirement has probably evolved as a mechanism to avoid promiscuous or unnecessary immune activation. As well as the interaction between the antigen-presenting MHC and the TCR, which provides the specificity of the response, another well-studied mechanism is costimulation, such as that conferred by the interaction between the B7 protein on antigenpresenting cells (APCs) and CD28 (also known as cytotoxic T-lymphocyte-associated protein 4) on T cells, which provides confirmation of appropriate context for the response $^{22,23}$. This second co-stimulatory signal on naive $\mathrm{T}$ cells is required for the production of IL-2, which helps to promote T-cell differentiation. TCR ligation in the absence of co-stimulation can result in antigen-specific T-cell anergy ${ }^{24}$. Following differentiation, the expression of CD28 is markedly downregulated and the resulting memory $\mathrm{T}$ cells no longer require co-stimulation for secondary immune responses. Thus, the lack of CD28 expression is an important hallmark of an antigen-experienced cell in humans and non-human primates ${ }^{25}$.

The requirement for co-stimulation in T-cell differentiation forms the basis of the development of therapeutic agents designed to block the interaction between B7 and CD28, with the aim of rendering cells anergic that would otherwise respond to de novo alloantigens. One such agent, belatacept - a fusion protein that specifically blocks the costimulatory CD28-B7 interaction - has elevated the profile of memory T cells in transplant immunotherapeutics, as memory $\mathrm{T}$ cells from prior antigen exposure that no longer require co-stimulation might cross-react with alloantigens (see below).

\section{Adhesion molecule expression}

Following an antigen encounter in the presence of CD28 co-stimulation, a naive $\mathrm{T}$ cell loses CD28 expression and gains the expression of adhesion molecules such as CD2, leukocyte function-associated antigen-1 (LFA-1) and very late antigen-4 (VLA-4). CD2 aids T-cell activation and adhesion by binding to LFA-3 on APCs and inflamed tissues ${ }^{26,27}$. LFA-1 and VLA-4 bind intercellular adhesion molecule-1 (ICAM-1) and vascular cell adhesion molecule-1 (VCAM-1), respectively, on activated peripheral vascular endothelium at sites of inflammation, and are involved in cell migration and extravasation required for effector functions ${ }^{28-30}$.

\section{Allograft rejection}

Alloreactive memory T cells-Effector and memory T cells downregulate CD28 and upregulate the expression of adhesion molecules; however, the precise triggers that induce these differentiation pathways remain incompletely defined. Regardless, co-stimulation promotes the differentiation of naive $\mathrm{T}$ cells into memory $\mathrm{T}$ cells. The lack of requirement for further co-stimulation combined with the increased expression of adhesion molecules enables these cells to quickly activate and infiltrate inflamed tissues in the periphery to exert their effector function after re-encountering the same antigen. By their very nature, however, 
effector memory $\mathrm{T}$ cells are potent mediators of rejection — their low threshold requirement for activation and high levels of adhesion molecules facilitate access to the transplanted tissue $^{31}$ - and clinical observations have revealed that increased levels of donor-specific, cytokine-producing memory $\mathrm{T}$ cells correlate with high instances of rejection and poor longterm allograft survival ${ }^{32,33}$.

Indeed, effector cells that express low levels of CD28 have been implicated in CD28-B7 costimulation-blockade-resistant allograft rejection ${ }^{34,35}$. Other subsets of CD28- $\mathrm{T}$ cells that also express high levels of CD2, LFA-1 and VLA-4, are associated with rejection mediated by resistance to belatacept in human studies ${ }^{36}$. These data indicate that co-stimulation blockade, although effective at inhibiting responses to de novo alloantigens, is inadequate at inhibiting pre-existing allospecific memory T-cell responses.

Cross-reactivity—Exposure to alloantigens, as might occur through pregnancy, blood transfusion or prior allograft transplantation, has the potential to generate populations of donor-reactive memory $\mathrm{T}$ cells. Furthermore, memory $\mathrm{T}$ cells generated in response to prior viral or bacterial infections also have the potential to cross-react with alloantigens ${ }^{37,38}$. This cross-reaction exemplifies the biological concept of heterologous immunity - memory responses derived from non-identical but similar antigens — and is likely to have a dynamic role in shaping the alloimmune repertoire of an individual ${ }^{39}$. Indeed, rapidly expanding populations of heterologous, cross-reactive memory $\mathrm{T}$ cells confer a survival advantage over non-cross-reactive cells, such that heterologously reactive cells become immunodominant. This process occurs especially in the context of viral infection, during which heterologously reactive memory $\mathrm{T}$ cells from past immune experience respond quickly to new infections, enabling the expansion and continued selection of memory $\mathrm{T}$ cells that yield superior protection compared to non-cross-reactive cells ${ }^{40}$. Notably, a breadth of alloreactivity exists in the human immune cell repertoire, such that $\mathrm{T}$ cells that respond to donor antigens reside in naive and memory compartments ${ }^{21,41}$. This phenomenon is not observed in experimental mice owing to their relatively limited antigen experience. The lack of heterologous reactivity is a considerable difference to consider when utilizing such mice to model human conditions.

The ability of memory $\mathrm{T}$ cells generated in response to prior infections to cross-react with different antigens confers an evolutionary benefit by providing a broader spectrum of immunity ${ }^{42}$, thereby generating a heterologous memory that can fend off a greater variety of pathogens with a less diverse TCR repertoire. This cross-reactivity is detrimental, however, in the case of allotransplantation. Adams et al. elegantly showed that memory $\mathrm{T}$ cells from mice that had multiple infections could cross-react with alloantigens and mediate the rejection of skin allografts in the setting of co-stimulation blockade ${ }^{43}$. Specific pathogens such as Listeria monocytogenes ${ }^{44}, \gamma$-herpes virus ${ }^{45}$ and cytomegalovirus (CMV) ${ }^{46,47}$ have been mechanistically defined in heterologous alloimmune processes. Indeed, in mice, these infections drive T-cell differentiation and the loss of CD28 expression, leading to indifference to CD28-B7 co-stimulation blockade ${ }^{35}$. This type of direct alloresponse might be an acute, rather than chronic, problem in transplant recipients, and understanding the spectrum of phenotypes and activation criteria of memory $\mathrm{T}$ cells could help to elucidate a 
means of specifically targeting alloreactive $\mathrm{T}$ cells without compromising host protective immunity.

The distinction in the literature between effector and memory $\mathrm{T}$ cell phenotypes in the context of allograft rejection has been unclear. Lakkis and colleagues demonstrated the dependence of naive T cells on interactions with APCs in secondary lymphoid organs for the initiation of alloimmune responses $3,48,49$. Without these organized interactions, the immune system remains ignorant of alloantigens, resulting in peripheral tolerance. By contrast, memory $\mathrm{T}$ cells in the periphery can expand and effectively induce rejection of an allograft independent of secondary lymphoid organs. Similarly, the presence of heterologously alloreactive memory $\mathrm{T}$ cells can induce rejection despite treatment with otherwise effective immune regimens ${ }^{43}$.

Ischaemia and graft-intrinsic factors-Trauma and ischaemia are inherent to organ procurement and transplantation, and invariably lead to the generation of reactive oxygen species and the release of damage-associated molecular patterns (that is, host-derived molecules that can induce a nonpathogenic inflammatory response) and cytokines. In the case of transplantation, these pro-inflammatory processes might originate within the donor before organ recovery ${ }^{50}$. Although the response to ischaemic injury is thought to be primarily mediated through an innate immune response, emerging evidence points towards the existence of a substantial involvement of $\mathrm{T}$ cells ${ }^{51}$. In the presence of ischaemic organ injury ${ }^{52}$, ambient inflammatory factors might further lower the activation thresholds of memory $\mathrm{T}$ cells that have a subthreshold affinity for a given antigen. Using a mouse model of heterotopic heart transplantation, Fairchild et al. demonstrated that prolonged ischaemia leads to infiltration by endogenous memory $\mathrm{CD}^{+} \mathrm{T}$ cells and rejection in the setting of costimulation blockade ${ }^{34}$.

Evidence supporting the contribution of graft-specific factors, such as complement, to allograft rejection has also emerged ${ }^{53}$. Pratt et al. showed that intrinsic donor, but not recipient, complement can trigger the prominent migration of effector memory $\mathrm{T}$ cells and augment allospecific T-cell responses ${ }^{54}$, demonstrating that memory $\mathrm{T}$ cells can respond to insults in the periphery through complement receptors ${ }^{55}$. Indeed, memory $\mathrm{T}$ cells are readily activated not only by re-exposure to antigens, but also by factors produced as a result of ischaemia and peripheral injury - properties that make these cells effective for rapid recall to lytic viruses for example, but also present considerable issues in transplantation.

\section{Targeting alloreactive memory cells}

\section{Detection}

Memory $\mathrm{T}$ cells will have no impact on an allograft unless they are specific for certain allogeneic antigens. Moreover, certain memory T-cell subsets have a regulatory role, meaning that not all alloreactive T-cell memory necessarily has an adverse impact on the transplant ${ }^{56-59}$. Thus, it is not simply the presence of memory, but the presence of memory with specificity to donor antigen, that poses a problem in the context of organ transplantation. As a stochastic overlap exists between all memory $\mathrm{T}$ cells and the protective 
immune alloreactive population, the need for assays to detect alloreactive memory $\mathrm{T}$ cells is considerable.

Historically, cytotoxicity assays, such as chromium-release assays or mixed lymphocyte reactions, have been used to detect alloreactive memory $\mathrm{T}$ cells, although memory-specific traits have not been well established. Hricik et al. ${ }^{60}$ and Bestard et al..$^{60,61}$ demonstrated that enzyme-linked immunosorbent spot assays that measure the production of interferon- $\gamma$ seem to detect memory $\mathrm{T}$ cells in the periphery, and that this assay could be a surrogate marker for long-term graft function and enable patient stratification. Numerous transplant immune therapeutics are available that target molecules differentially expressed on memory $\mathrm{T}$ cells, and the ability to detect and specifically target alloreactive memory $\mathrm{T}$ cells is paramount to improve the outcome of transplantation.

\section{T-cell depletion and homeostatic proliferation}

One method to address the issue of the presence of alloreactive memory $\mathrm{T}$ cells at the time of transplantation is to nonspecifically eliminate them. Rabbit antithymocyte globulin (rATG) is the most commonly used induction therapy in current clinical practice; this agent induces profound depletion of $\mathrm{T}$ cells and apoptosis in B-cell subsets, and interferes with the function of dendritic cells, the development of regulatory $\mathrm{T}\left(\mathrm{T}_{\mathrm{REG}}\right)$ cells and remodelling of immune cells ${ }^{62,63}$. Alemtuzumab, a monoclonal antibody preparation targeting the cellsurface protein CD52, is also highly effective at depleting peripheral and secondary lymphoid $\mathrm{T}$ and $\mathrm{B}$ cells ${ }^{64}$. Although $\mathrm{rATG}$ and alemtuzumab bring about profound T-cell depletion, they have heterogeneous effects on naive and memory T cells. Murine and clinical studies have demonstrated that T-cell populations show differential susceptibility to depletion: memory cells are not depleted as effectively as naive cells, causing a predominance of the memory phenotype during homeostatic repopulation ${ }^{65-67}$. This finding probably explains the ability of transplant recipients to tolerate severe lymphopenia with comparatively little opportunistic infection compared with, for example, patients with lymphopenia as a consequence of HIV infection.

$\mathrm{T}$ cells generated through homeostatic repopulation differ from conventional memory $\mathrm{T}$ cells in that they only require the presence of self peptide-MHC complexes ${ }^{68}$ and are generated without the need for IL-2 or CD28 co-stimulation ${ }^{69}$. These cells have been termed 'pseudomemory' cells to indicate initial inferior function owing to antigen-independent differentiation, but progressively become more functionally responsive ${ }^{49,67,70,71}$. Sener et al. demonstrated that this phenotype might emerge from the naive compartment with a linear shift to memory ${ }^{72}$. Thus, not only are memory $\mathrm{T}$ cells resistant to depletion, but any residual naive $\mathrm{T}$ cells undergo substantial homeostatic expansion that results in the acquisition of functional memory T cells. Despite the turnover of naive T cells, co-stimulation blockade neither suppresses homeostatic proliferation nor prevents allograft rejection, probably because of the CD28-co-stimulation independence of $\mathrm{T}$ cells during homeostatic repopulation ${ }^{71,73}$. Irrespective, these cells maintain functional capacity, suggesting that the benefits of T-cell depletion are reduced by the activation of homeostatic reconstitution.

Mechanistic studies have begun to reveal how homeostatic repopulation can be manipulated to favour an allotolerant repertoire ${ }^{74}$. Indeed, depletion therapy can induce donor-specific 
hyporesponsiveness, although the mechanisms might depend on the adjuvant immunosuppression being used at the time of depletion ${ }^{75-77}$. In general, depletion might present a unique opportunity to shape the immune cell repertoire. Studies of alemtuzumabmediated depletion in combination with belatacept and sirolimus (which inhibits IL-2 production) have shown that the burst of homeostatic activation is countered by a corresponding burst of $\mathrm{T}_{\mathrm{REG}}$ and $\mathrm{B}_{\mathrm{REG}}$ cell generation, and that this phenomenon is associated with exceptionally low rates of rejection ${ }^{78}$. This approach might offer an opportunity to specifically target the nutritional requirements of memory $\mathrm{T}$ cells in order to shape the immune-cell repertoire and aid in the elimination of allospecific effector memory T cells.

\section{Inhibition of allospecific T-cell function}

Drugs capable of impeding allospecific T-cell functions are key to the success of organ transplantation. Two such prominent agents are calcineurin inhibitors (CNIs) ${ }^{79-82}$ and mammalian target of rapamycin (mTOR) inhbitors, both of which form complexes with FK506-binding proteins (FKBP) to inhibit lymphocyte activation pathways (FIG. 2), and have distinct effects on $\mathrm{T}$ cells of varying states of differentiation.

Calcineurin inhibitors-The CNIs ciclosporin A and tacrolimus prevent T-cell proliferation and cytokine production by inhibiting calcineurin and subsequent signalling by nuclear factor of activated $\mathrm{T}$ cells, which effectively suppresses TCR-mediated activation regardless of the maturation state of the cell ${ }^{21}$. Even at low doses, CNIs prevent the activation and maturation of naive $\mathrm{T}$ cells as well as simultaneously inhibiting the activation of memory $\mathrm{T}$ cells and their cytokine production ${ }^{83}$. Tacrolimus indiscriminately inhibits CMV-specific and allospecific memory T cells, whereas belatacept results in a differential effect based on maturation status ${ }^{21}$. This broad, but highly effective, mode of immunosuppression has made CNIs a front-line therapy in conventional immunosuppression regimens, but also significantly hinders protective immunity resulting in an increased risk of infection.

mTOR inhibitors-T-cell maturation induces various metabolic alterations that affect the differentiation and activation of these cells; inhibiting the activation of mTOR fundamentally alters this metabolic programming ${ }^{84}$. mTOR induces specific effects in $\mathrm{CD}^{+}$and $\mathrm{CD} 8^{+}$ memory $\mathrm{T}$ cells formed via homeostatic repopulation that are essential for preserving effector function ${ }^{85,86}$. Memory $\mathrm{CD} 4^{+} \mathrm{T}$ cells, in particular, depend on glycolysis for activation and effector function through phosphatidylinositol 3-kinase signalling downstream of $\mathrm{mTOR}^{87,88}$, whereas memory $\mathrm{CD}^{+} \mathrm{T}$ cells are more reliant on lipid metabolism for their activation and function ${ }^{89}$. Reliance on fatty acid oxidation could explain why sirolimus might cause an apparent increase in the formation of pathogenspecific memory CD8 ${ }^{+} \mathrm{T}$ cells ${ }^{90-92}$, while concurrently abating T-cell responses to alloantigens ${ }^{93}$. This metabolic shift could also explain how mTOR inhibition might have tolerance-inducing effects by augmenting the formation of $\mathrm{T}_{\mathrm{REG}}$ cells ${ }^{94}$. Thus, $\mathrm{mTOR}$ inhibition, through complex mechanisms, seems to divert normal T-cell development and memory formation by altering metabolic priority, potentially towards a phenotype that is more amenable to long-term allograft tolerance. 
Owing to their capacity to broadly suppress T-cell responses, CNIs and mTOR inhibitors have been readily incorporated into immunosuppressive regimens (FIG. 2). Agents with a more discriminating effect on memory $\mathrm{T}$ cells would, however, be preferable, provided that they exhibit a comparable efficacy in preventing rejection.

\section{Blocking differentiation}

The desire for targeted therapeutics has driven the development of numerous monoclonal antibodies and fusion proteins that show a high degree of specificity for molecules relevant to the differentiation of memory $\mathrm{T}$ cells. The majority of these agents have not yet been tested in patients.

Co-stimulation blockade-Blockade of co-stimulatory molecules has been a clinical focus in transplant immunosuppression and contributed to the FDA approval of belatacept for use in transplantation in 2011 (REF. 95). Belatacept was developed as a potential replacement for CNIs; its selective targeting of de novo allospecific responses has the advantage of sparing previously acquired protective immunity, but this selectivity has perhaps unveiled the importance of previously under-appreciated allospecific memory. Specifically, treatment with belatacept has proven to be ineffective in a substantial minority of patients, which has presented a hurdle to its clinical use.

In experimental models of transplantation in which immune tolerance has been achieved in the setting of co-stimulation blockade by CTLA4-Ig, introduction of donor-specific memory $\mathrm{T}$ cells has overcome this tolerance ${ }^{43,73,96}$. Furthermore, type $17 \mathrm{~T}$ helper $\left(\mathrm{T}_{\mathrm{H}} 17\right)$ cells, a pro-inflammatory memory subset of $\mathrm{CD} 4^{+} \mathrm{T}$ cells, express high levels of $\mathrm{CD} 28$ (which binds B7). Thus, $\mathrm{B} 7$ inhibition by belatacept might augment the potency of $\mathrm{T}_{\mathrm{H}} 17$ cells by preventing ligation of their co-inhibitory receptors. Indeed, an increase in the frequency of $\mathrm{T}_{\mathrm{H}} 17$ cells was associated with acute rejection in rodent models ${ }^{97}$.

Many other co-stimulatory molecules are under investigation as potential targets for immunosuppressive drugs, but the majority of data are from experimental studies, with clinical application currently in the conceptual stages. Preclinical studies of memory-specific agents have, however, demonstrated a potential adjuvant effect when combined with current co-stimulation blocking agents ${ }^{98,99,100-103}$.

Targeting co-stimulation and adhesion molecules-The distinct surface molecule expression and co-stimulatory requirements of memory $\mathrm{T}$ cells ${ }^{12,104}$ have been exploited experimentally in investigations combining blockade of co-stimulation with suppression of adhesion molecule expression (FIG. 2). For example, the LFA-3-Ig fusion protein, alefacept, targets memory $\mathrm{T}$ cells in psoriasis by inducing their apoptosis ${ }^{105}$, prompting investigation into its potential use in the setting of transplantation. The results of initial in vitro studies using alefacept in combination with co-stimulation blockade supported this strategy, showing the depletion of $\mathrm{CD}^{+}$memory $\mathrm{T}$ cells that were otherwise resistant to belatacept ${ }^{98}$. The combined use of alefacept and belatacept in non-human primate models of kidney transplantation resulted in the depletion of $\mathrm{CD}^{+}$and $\mathrm{CD} 8^{+}$effector memory $\mathrm{T}$ cells and improvement in allograft survival compared to co-stimulation blockade alone ${ }^{99}$. However, continued preclinical studies in kidney, islet and vascularized composite allograft tissue 
transplantation have - not unexpectedly - demonstrated a loss of protective immunity ${ }^{106-108}$, emphasizing the critical balance of memory-directed therapy required for protective immunity.

Similarly, studies of heterotopic heart transplants in a rodent model showed that blockade of LFA-1 prevented the early infiltration of alloreactive memory $T$ cells into the donor allograft ${ }^{109}$. These results correlate with those from other studies combining co-stimulation and adhesion molecule blockade to augment allograft survival. For example, the use of efalizumab, an LFA-1 antagonist, in islet transplantation in patients with type 1 diabetes mellitus improved long-term allograft survival and rates of single-donor insulin independence in conjunction with co-stimulation blockade ${ }^{110-112}$. Targeting VLA-4 in conjunction with co-stimulation blockade also increased survival in rodent transplant models compared to co-stimulation blockade alone ${ }^{113}$. Thus, inhibition of LFA-1 or VLA-4 in combination with co-stimulation blockade might have a synergistic effect, particularly in the setting of heterologous memory, whereby inhibition of integrin binding might selectively target cells that are resistant to co-stimulation blockade ${ }^{47,100}$.

This memory-focused therapeutic strategy, although efficacious, seems to have a narrow therapeutic window that will require additional investigation before a clinical strategy can be adopted. Efalizumab and alefacept both showed promise in abrogating memory-specific responses, prompting clinical trials and receiving initial commercial success for psoriasis, but were subsequently withdrawn from the market, citing loss of endogenous viral control as the main cause ${ }^{107,114}$. The risk:benefit balance of these agents in transplantation remains to be defined. Similarly, VLA-4 antagonists such as natalizumab require further preclinical and clinical studies to determine their potential in a clinical transplant setting.

\section{Conclusions}

Memory $\mathrm{T}$ cells, and their ability to generate an anamnestic response, are vital to protective immunity. Their altered expression of CD28 and adhesion molecules not only explains their physiologic value, but also provides insight into their potentially detrimental impact on allograft survival. These characteristics have been exploited by a growing number of immunosuppressive small molecules and biologics, and the judicious application of these agents has the potential to more finely control alloimmune responses while preserving protective immunity. Thus, the continued study of memory $\mathrm{T}$ cells and their unique properties will aid the development of novel immunosuppression strategies and optimize the application of currently available therapies. Furthermore, investigation into the formation of memory stem $\mathrm{T}$ cells (that is, a memory $\mathrm{T}$ cell subset with stem-cell-like properties) and the contribution of these cells to the immune response might provide insight into their potential role in allograft transplantation. Dedicated pursuit in understanding the formation, activation, and mechanisms of immunologic memory will be key to improving the success of allotransplantation.

\section{References}

1. Jameson SC, Masopust D. Diversity in T cell memory: an embarrassment of riches. Immunity. 2009; 31:859-871. [PubMed: 20064446] 
2. Sallusto F, Lenig D, Forster R, Lipp M, Lanzavecchia A. Two subsets of memory T lymphocytes with distinct homing potentials and effector functions. Nature. 1999; 401:708-712. [PubMed: 10537110]

3. Lakkis FG, Arakelov A, Konieczny BT, Inoue Y. Immunologic 'ignorance' of vascularized organ transplants in the absence of secondary lymphoid tissue. Nat Med. 2000; 6:686-688. [PubMed: 10835686]

4. Curtsinger JM, Lins DC, Mescher MF. CD8 ${ }^{+}$memory T cells $\left(\mathrm{CD} 44^{\text {high }}\right.$, Ly- $\left.6 \mathrm{C}^{+}\right)$are more sensitive than naive cells to (CD44 $\left.{ }^{\text {low }}, \mathrm{Ly}-6 \mathrm{C}\right)$ to TCR/CD8 signaling in response to antigen. $\mathrm{J}$ Immunol. 1998; 160:3236-3243. [PubMed: 9531279]

5. Wherry EJ. T cell exhaustion. Nat Immunol. 2011; 12:492-499. [PubMed: 21739672]

6. Chang JT, Wherry EJ, Goldrath AW. Molecular regulation of effector and memory T cell differentiation. Nat Immunol. 2014; 15:1104-1115. [PubMed: 25396352]

7. Wherry EJ, et al. Lineage relationship and protective immunity of memory CD8 T cell subsets. Nat Immunol. 2003; 4:225-234. [PubMed: 12563257]

8. Weninger W, Crowley MA, Manjunath N, von Andrian UH. Migratory properties of naive, effector, and memory CD8 ${ }^{+}$T cells. J Exp Med. 2001; 194:953-966. [PubMed: 11581317]

9. Baron $\mathrm{V}$, et al. The repertoires of circulating human $\mathrm{CD} 8^{+}$central and effector memory $\mathrm{T}$ cell subsets are largely distinct. Immunity. 2003; 18:193-204. [PubMed: 12594947]

10. Lanzavecchia A, Sallusto F. Dynamics of T lymphocyte responses: intermediates, effectors, and memory cells. Science. 2000; 290:92-97. [PubMed: 11021806]

11. Iezzi G, Karjalainen K, Lanzavecchia A. The duration of antigenic stimulation determines the fate of naive and effector T cells. Immunity. 1998; 8:89-95. [PubMed: 9462514]

12. Kaech SM, Wherry EJ, Ahmed R. Effector and memory T-cell differentiation: implications for vaccine development. Nat Rev Immunol. 2002; 2:251-262. [PubMed: 12001996]

13. Gerlach C, et al. One naive $\mathrm{T}$ cell, multiple fates in $\mathrm{CD}^{+} \mathrm{T}$ cell differentiation. J Exp Med. 2010; 207:1235-1246. [PubMed: 20479114]

14. Stemberger $\mathrm{C}$, et al. A single naive $\mathrm{CD}^{+} \mathrm{T}$ cell precursor can develop into diverse effector and memory subsets. Immunity. 2007; 27:985-997. [PubMed: 18082432]

15. Gaide $\mathrm{O}$, et al. Common clonal origin of central and resident memory $\mathrm{T}$ cells following skin immunization. Nat Med. 2015; 21:647-653. [PubMed: 25962122]

16. Grakoui A, et al. The immunological synapse: a molecular machine controlling $\mathrm{T}$ cell activation. Science. 1999; 285:221-227. [PubMed: 10398592]

17. Chang JT, et al. Asymmetric proteasome segregation as a mechanism for unequal partitioning of the transcription factor T-bet during T lymphocyte division. Immunity. 2011; 34:492-504. [PubMed: 21497118]

18. Chang JT, et al. Asymmetric T lymphocyte division in the initiation of adaptive immune responses. Science. 2007; 315:1687-1691. [PubMed: 17332376]

19. Kinjyo I, et al. Real-time tracking of cell cycle progression during $\mathrm{CD}^{+}$effector and memory Tcell differentiation. Nat Commun. 2015; 6:6301. [PubMed: 25709008]

20. Manjunath N, et al. Effector differentiation is not prerequisite for generation of memory cytotoxic T lymphocytes. J Clin Invest. 2001; 108:871-878. [PubMed: 11560956]

21. Xu H, Perez SD, Cheeseman J, Mehta AK, Kirk AD. The allo-and viral-specific immunosuppressive effect of belatacept, but not tacrolimus, attenuates with progressive $\mathrm{T}$ cell maturation. Am J Transplant. 2014; 14:319-332. [PubMed: 24472192]

22. Guerder S, Carding SR, Flavell RA. B7 costimulation is necessary for the activation of the lytic function in cytotoxic T lymphocyte precursors. J Immunol. 1995; 155:5167-5174. [PubMed: 7594526]

23. Turka LA, Ledbetter JA, Lee K, June CH, Thompson CB. CD28 is an inducible T cell surface antigen that transduces a proliferative signal in $\mathrm{CD}^{+}$mature thymocytes. J Immunol. 1990; 144:1646-1653. [PubMed: 2155264]

24. Chen L, Flies DB. Molecular mechanisms of T cell co-stimulation and co-inhibition. Nat Rev Immunol. 2013; 13:227-242. [PubMed: 23470321] 
25. Mou D, Espinosa J, Lo DJ, Kirk AD. CD28 negative T cells: is their loss our gain? Am J Transplant. 2014; 14:2460-2466. [PubMed: 25323029]

26. Selvaraj $\mathrm{P}$, et al. The T lymphocyte glycoprotein CD2 binds the cell surface ligand LFA-3. Nature. 1987; 326:400-403. [PubMed: 2951597]

27. Semnani RT, Nutman TB, Hochman P, Shaw S, van Seventer GA. Costimulation by purified intercellular adhesion molecule 1 and lymphocyte function-associated antigen 3 induces distinct proliferation, cytokine and cell surface antigen profiles in human 'naive' and 'memory' $\mathrm{CD}_{4}^{+} \mathrm{T}$ cells. J Exp Med. 1994; 180:2125-2135. [PubMed: 7525848]

28. Yusuf-Makagiansar H, Anderson ME, Yakovleva TV, Murray JS, Siahaan TJ. Inhibition of LFA-1/ ICAM-1 and VLA-4/VCAM-1 as a therapeutic approach to inflammation and autoimmune diseases. Med Res Rev. 2002; 22:146-167. [PubMed: 11857637]

29. Nicolls MR, Gill RG. LFA-1 (CD11a) as a therapeutic target. Am J Transplant. 2006; 6:27-36. [PubMed: 16433753]

30. Kim TK, Billard MJ, Wieder ED, McIntyre BW, Komanduri KV. Co-engagement of $\alpha_{4} \beta_{1}$ integrin (VLA-4) and CD4 or CD8 is necessary to induce maximal Erk1/2 phosphorylation and cytokine production in human T cells. Hum Immunol. 2010; 71:23-28. [PubMed: 19815047]

31. Krummey SM, Ford ML. Heterogeneity within T cell memory: implications for transplant tolerance. Front Immunol. 2012; 3:36. [PubMed: 22566919]

32. Heeger PS, et al. Pretransplant frequency of donor-specific, IFN- $\gamma$-producing lymphocytes is a manifestation of immunologic memory and correlates with the risk of posttransplant rejection episodes. J Immunol. 1999; 163:2267-2275. [PubMed: 10438971]

33. San Segundo D, et al. Increased numbers of circulating CD8 effector memory T cells before transplantation enhance the risk of acute rejection in lung transplant recipients. PLoS ONE. 2013; 8:e80601. [PubMed: 24236187]

34. Su CA, Iida S, Abe T, Fairchild RL. Endogenous memory CD8 T cells directly mediate cardiac allograft rejection. Am J Transplant. 2014; 14:568-579. [PubMed: 24502272]

35. Mou D, Espinosa JE, Stempora L, Iwakoshi NN, Kirk AD. Viral-induced CD28 loss evokes costimulation independent alloimmunity. J Surg Res. 2015; 196:241-246. [PubMed: 25801976]

36. Espinosa, JR., et al. CD $57^{+} \mathrm{CD} 4 \mathrm{~T}$ cells underlie belatacept-resistant allograft rejection. Am J Transplant. 2016. http://dx.doi.org/10.1111/ajt.13613

37. Landais E, et al. EBV-specific $\mathrm{CD} 4^{+} \mathrm{T}$ cell clones exhibit vigorous allogeneic responses. J Immunol. 2006; 177:1427-1433. [PubMed: 16849448]

38. Burrows SR, et al. Cross-reactive memory T cells for Epstein-Barr virus augment the alloresponse to common human leukocyte antigens: degenerate recognition of major histocompatibility complex-bound peptide by T cells and its role in alloreactivity. Eur J Immunol. 1997; 27:17261736. [PubMed: 9247584]

39. Pantenburg B, Heinzel F, Das L, Heeger PS, Valujskikh A. T cells primed by Leishmania major infection cross-react with alloantigens and alter the course of allograft rejection. J Immunol. 2002; 169:3686-3693. [PubMed: 12244161]

40. Brehm MA, et al. T cell immunodominance and maintenance of memory regulated by unexpectedly cross-reactive pathogens. Nat Immunol. 2002; 3:627-634. [PubMed: 12055626]

41. Macedo $\mathrm{C}$, et al. Contribution of naive and memory T-cell populations to the human alloimmune response. Am J Transplant. 2009; 9:2057-2066. [PubMed: 19624567]

42. Welsh RM, Selin LK. No one is naive: the significance of heterologous T-cell immunity. Nat Rev Immunol. 2002; 2:417-426. [PubMed: 12093008]

43. Adams AB, et al. Heterologous immunity provides a potent barrier to transplantation tolerance. $\mathrm{J}$ Clin Invest. 2003; 111:1887-1895. [PubMed: 12813024]

44. Wang T, et al. Prevention of allograft tolerance by bacterial infection with. Listeria monocytogenes J Immunol. 2008; 180:5991-5999. [PubMed: 18424719]

45. Stapler D, et al. Expansion of effector memory TCR V $34^{+} \mathrm{CD} 8^{+} \mathrm{T}$ cells is associated with latent infection-mediated resistance to transplantation tolerance. J Immunol. 2008; 180:3190-3200. [PubMed: 18292543]

46. Williams MA, et al. Characterization of virus-mediated inhibition of mixed chimerism and allospecific tolerance. J Immunol. 2001; 167:4987-4995. [PubMed: 11673506] 
47. Beus JM, et al. Heterologous immunity triggered by a single, latent virus in Mus musculus: combined costimulation-and adhesion-blockade decrease rejection. PLoS ONE. 2013; 8:e71221. [PubMed: 23940724]

48. Oberbarnscheidt MH, et al. Memory T cells migrate to and reject vascularized cardiac allografts independent of the chemokine receptor CXCR3. Transplantation. 2011; 91:827-832. [PubMed: 21285915]

49. Chalasani G, Dai Z, Konieczny BT, Baddoura FK, Lakkis FG. Recall and propagation of allospecific memory T cells independent of secondary lymphoid organs. Proc Natl Acad Sci USA. 2002; 99:6175-6180. [PubMed: 11983909]

50. Watts RP, Thom O, Fraser JF. Inflammatory signalling associated with brain dead organ donation: from brain injury to brain stem death and posttransplant ischaemia reperfusion injury. J Transplant. 2013; 2013:521369. [PubMed: 23691272]

51. Takada M, Chandraker A, Nadeau KC, Sayegh MH, Tilney NL. The role of the B7 costimulatory pathway in experimental cold ischemia/reperfusion injury. J Clin Invest. 1997; 100:1199-1203. [PubMed: 9276737]

52. Rao J, Lu L, Zhai Y. T cells in organ ischemia reperfusion injury. Curr Opin Organ Transplant. 2014; 19:115-120. [PubMed: 24576906]

53. Asgari E, Farrar CA, Sacks SH. Control of innate immunological mechanisms as a route to drug minimization. Curr Opin Organ Transplant. 2014; 19:342-347. [PubMed: 24905023]

54. Pratt JR, Basheer SA, Sacks SH. Local synthesis of complement component C3 regulates acute renal transplant rejection. Nat Med. 2002; 8:582-587. [PubMed: 12042808]

55. Kirk AD. Location, location, location: regional immune mechanisms critically influence rejection. Nat Med. 2002; 8:553-555. [PubMed: 12042797]

56. Krupnick AS, et al. Central memory $\mathrm{CD}^{+} \mathrm{T}$ lymphocytes mediate lung allograft acceptance. J Clin Invest. 2014; 124:1130-1143. [PubMed: 24569377]

57. Li S, et al. A naturally occurring $\mathrm{CD} 8^{+} \mathrm{CD} 122^{+}$T-cell subset as a memory-like Treg family. Cell Mol Immunol. 2014; 11:326-331. [PubMed: 24793406]

58. Wan $\mathrm{N}$, et al. Bystander central memory but not effector memory $\mathrm{CD}^{+} \mathrm{T}$ cells suppress allograft rejection. J Immunol. 2008; 180:113-121. [PubMed: 18097010]

59. Popescu I, et al. EBV-specific $\mathrm{CD}^{+} \mathrm{T}$ cell reactivation in transplant patients results in expansion of $\mathrm{CD}^{+}$type-1 regulatory T cells. Am J Transplant. 2007; 7:1215-1223. [PubMed: 17331111]

60. Hricik DE, et al. Enzyme linked immunosorbent spot (ELISPOT) assay for interferon-gamma independently predicts renal function in kidney transplant recipients. Am J Transplant. 2003; 3:878-884. [PubMed: 12814480]

61. Bestard O, et al. Cross-validation of IFN- $\gamma$ Elispot assay for measuring alloreactive memory/ effector T cell responses in renal transplant recipients. Am J Transplant. 2013; 13:1880-1890. [PubMed: 23763435]

62. Mohty M. Mechanisms of action of antithymocyte globulin: T-cell depletion and beyond. Leukemia. 2007; 21:1387-1394. [PubMed: 17410187]

63. LaCorcia G, et al. Polyclonal rabbit antithymocyte globulin exhibits consistent immunosuppressive capabilities beyond cell depletion. Transplantation. 2009; 87:966-974. [PubMed: 19352114]

64. Kirk AD, et al. Results from a human renal allograft tolerance trial evaluating the humanized CD52-specific monoclonal antibody alemtuzumab (CAMPATH-1H). Transplantation. 2003; 76:120-129. [PubMed: 12865797]

65. Neujahr DC, et al. Accelerated memory cell homeostasis during $\mathrm{T}$ cell depletion and approaches to overcome it. J Immunol. 2006; 176:4632-4639. [PubMed: 16585554]

66. Goldrath AW, Bogatzki LY, Bevan MJ. Naive T cells transiently acquire a memory-like phenotype during homeostasis-driven proliferation. J Exp Med. 2000; 192:557-564. [PubMed: 10952725]

67. Pearl JP, et al. Immunocompetent T-cells with a memory-like phenotype are the dominant cell type following antibody-mediated T-cell depletion. Am J Transplant. 2005; 5:465-474. [PubMed: 15707400]

68. Viret C, Wong FS, Janeway CA Jr. Designing and maintaining the mature TCR repertoire. Immunity. 1999; 10:559-568. [PubMed: 10367901] 
69. Cho BK, Rao VP, Ge Q, Eisen HN, Chen J. Homeostasis-stimulated proliferation drives naive T cells to differentiate directly into memory T cells. J Exp Med. 2000; 192:549-556. [PubMed: $10952724]$

70. Murali-Krishna K, Ahmed R. Cutting edge: naive T cells masquerading as memory cells. J Immunol. 2000; 165:1733-1737. [PubMed: 10925249]

71. Tchao NK, Turka LA. Lymphodepletion and homeostatic proliferation: implications for transplantation. Am J Transplant. 2012; 12:1079-1090. [PubMed: 22420320]

72. Sener A, Tang AL, Farber DL. Memory T-cell predominance following T-cell depletional therapy derives from homeostatic expansion of naive T cells. Am J Transplant. 2009; 9:2615-2623. [PubMed: 19775313]

73. Wu Z, et al. Homeostatic proliferation is a barrier to transplantation tolerance. Nat Med. 2004; 10:87-92. [PubMed: 14647496]

74. Stock P, Kirk AD. The risk and opportunity of homeostatic repopulation. Am J Transplant. 2011; 11:1349-1350. [PubMed: 21564527]

75. Cherkassky L, et al. Evaluation of alloreactivity in kidney transplant recipients treated with antithymocyte globulin versus IL-2 receptor blocker. Am J Transplant. 2011; 11:1388-1396. [PubMed: 21564525]

76. Trzonkowski P, Zilvetti M, Friend P, Wood KJ. Recipient memory-like lymphocytes remain unresponsive to graft antigens after CAMPATH-1H induction with reduced maintenance immunosuppression. Transplantation. 2006; 82:1342-1351. [PubMed: 17130784]

77. Kirk AD, et al. Renal transplantation using belatacept without maintenance steroids or calcineurin inhibitors. Am J Transplant. 2014; 14:1142-1151. [PubMed: 24684552]

78. $\mathrm{Xu}, \mathrm{H}$., et al. Postdepletional lymphocyte reconstitution during belatacept and rapamycin treatment in kidney transplant recipients. Am J Transplant. 2015. http://dx.doi.org/10.1111/ajt.13469

79. Calne RY, White DJ, Rolles K, Smith DP, Herbertson BM. Prolonged survival of pig orthotopic heart grafts treated with cyclosporin A. Lancet. 1978; 1:1183-1185. [PubMed: 77948]

80. Webster AC, Woodroffe RC, Taylor RS, Chapman JR, Craig JC. Tacrolimus versus ciclosporin as primary immunosuppression for kidney transplant recipients: meta-analysis and meta-regression of randomised trial data. 2005; 331:810.

81. Trompeter R, et al. Randomized trial of tacrolimus versus cyclosporin microemulsion in renal transplantation. Pediatr Nephrol. 2002; 17:141-149. [PubMed: 11956848]

82. Haddad EM, et al. Cyclosporin versus tacrolimus for liver transplanted patients. Cochrane Database Syst Rev. 2006; 18:CD005161.

83. Tsuda K, et al. Calcineurin inhibitors suppress cytokine production from memory T cells and differentiation of naive T cells into cytokine-producing mature T cells. PLoS ONE. 2012; 7:e31465. [PubMed: 22359594]

84. Pollizzi KN, Powell JD. Integrating canonical and metabolic signalling programmes in the regulation of T cell responses. Nat Rev Immunol. 2014; 14:435-446. [PubMed: 24962260]

85. Chen $\mathrm{S}$, et al. Effect of inhibiting the signal of mammalian target of rapamycin on memory $\mathrm{T}$ cells. Transplant Proc. 2014; 46:1642-1648. [PubMed: 24935341]

86. Li Q, et al. A central role for mTOR kinase in homeostatic proliferation induced $\mathrm{CD} 8^{+} \mathrm{T}$ cell memory and tumor immunity. Immunity. 2011; 34:541-553. [PubMed: 21511183]

87. Maekawa Y, et al. Notch controls the survival of memory $\mathrm{CD} 4^{+} \mathrm{T}$ cells by regulating glucose uptake. Nat Med. 2015; 21:55-61. [PubMed: 25501905]

88. Michalek RD, et al. Cutting edge: distinct glycolytic and lipid oxidative metabolic programs are essential for effector and regulatory CD4 ${ }^{+}$T cell subsets. J Immunol. 2011; 186:3299-3303. [PubMed: 21317389]

89. van der Windt GJ, et al. Mitochondrial respiratory capacity is a critical regulator of $\mathrm{CD}^{+} \mathrm{T}$ cell memory development. Immunity. 2012; 36:68-78. [PubMed: 22206904]

90. Araki K, et al. mTOR regulates memory CD8 T-cell differentiation. Nature. 2009; 460:108-112. [PubMed: 19543266] 
91. Brown NF, Stefanovic-Racic M, Sipula IJ, Perdomo G. The mammalian target of rapamycin regulates lipid metabolism in primary cultures of rat hepatocytes. Metabolism - Clin Exp. 2007; 56:1500-1507.

92. Pearce EL, et al. Enhancing CD8 T-cell memory by modulating fatty acid metabolism. Nature. 2009; 460:103-107. [PubMed: 19494812]

93. Ferrer IR, et al. Cutting edge: rapamycin augments pathogen-specific but not graft-reactive $\mathrm{CD}^{+} \mathrm{T}$ cell responses. J Immunol. 2010; 185:2004-2008. [PubMed: 20631309]

94. Gao W, et al. Contrasting effects of cyclosporine and rapamycin in de novo generation of alloantigen-specific regulatory T cells. Am J Transplant. 2007; 7:1722-1732. [PubMed: 17511761]

95. Wekerle T, Grinyo JM. Belatacept: from rational design to clinical application. Transpl Int. 2012; 25:139-150. [PubMed: 22151353]

96. Valujskikh A, Pantenburg B, Heeger PS. Primed allospecific T cells prevent the effects of costimulatory blockade on prolonged cardiac allograft survival in mice. Am J Transplant. 2002; 2:501-509. [PubMed: 12118893]

97. Krummey SM, et al. High CTLA-4 expression on Th17 cells results in increased sensitivity to CTLA-4 coinhibition and resistance to belatacept. Am J Transplant. 2014; 14:607-614. [PubMed: 24730049]

98. Lo DJ, et al. Selective targeting of human alloresponsive $\mathrm{CD} 8^{+}$effector memory $\mathrm{T}$ cells based on CD2 expression. Am J Transplant. 2011; 11:22-33. [PubMed: 21070604]

99. Weaver TA, et al. Alefacept promotes co-stimulation blockade based allograft survival in nonhuman primates. Nat Med. 2009; 15:746-749. [PubMed: 19584865]

100. Kitchens WH, et al. Integrin antagonists prevent costimulatory blockade-resistant transplant rejection by $\mathrm{CD}^{+}$memory T cells. Am J Transplant. 2012; 12:69-80. [PubMed: 21942986]

101. Anderson, DJ., et al. Anti-leukocyte function-associated antigen 1 therapy in a nonhuman primate renal transplant model of costimulation blockade-resistant rejection. Am J Transplant. 2016. http://dx.doi.org/10.1111/ajt.13628

102. Lo DJ, et al. A pilot trial targeting the ICOS-ICOS-L pathway in nonhuman primate kidney transplantation. Am J Transplant. 2015; 15:984-992. [PubMed: 25703015]

103. Badell IR, et al. LFA-1-specific therapy prolongs allograft survival in rhesus macaques. J Clin Invest. 2010:4520-4531. [PubMed: 21099108]

104. Li XC, Rothstein DM, Sayegh MH. Costimulatory pathways in transplantation: challenges and new developments. Immunol Rev. 2009; 229:271-293. [PubMed: 19426228]

105. da Silva AJ, et al. Alefacept, an immunomodulatory recombinant LFA-3/IgG1 fusion protein, induces CD16 signaling and CD2/CD16-dependent apoptosis of CD2 ${ }^{+}$cells. J Immunol. 2002; 168:4462-4471. [PubMed: 11970990]

106. Lowe MC, et al. Belatacept and sirolimus prolong nonhuman primate islet allograft survival: adverse consequences of concomitant alefacept therapy. Am J Transplant. 2013; 13:312-319. [PubMed: 23279640]

107. Lo DJ, et al. Belatacept and sirolimus prolong nonhuman primate renal allograft survival without a requirement for memory T cell depletion. Am J Transplant. 2013; 13:320-328. [PubMed: 23311611]

108. Freitas AM, et al. Studies introducing costimulation blockade for vascularized composite allografts in nonhuman primates. Am J Transplant. 2015; 15:2240-2249. [PubMed: 26139552]

109. Setoguchi K, et al. LFA-1 antagonism inhibits early infiltration of endogenous memory CD8 T cells into cardiac allografts and donor-reactive T cell priming. Am J Transplant. 2011; 11:923935. [PubMed: 21466654]

110. Posselt AM, et al. Islet transplantation in type 1 diabetics using an immunosuppressive protocol based on the anti-LFA-1 antibody efalizumab. Am J Transplant. 2010; 10:1870-1880. [PubMed: 20659093]

111. Posselt AM, et al. Islet transplantation in type 1 diabetic patients using calcineurin inhibitor-free immunosuppressive protocols based on T-cell adhesion or costimulation blockade. Transplantation. 2010; 90:1595-1601. [PubMed: 20978464] 
112. Turgeon NA, et al. Experience with a novel efalizumab-based immunosuppressive regimen to facilitate single donor islet cell transplantation. Am J Transplant. 2010; 10:2082-2091. [PubMed: 20883542]

113. Isobe $\mathrm{M}$, et al. Immunosuppression to cardiac allografts and soluble antigens by anti-vascular cellular adhesion molecule-1 and anti-very late antigen-4 monoclonal antibodies. J Immunol. 1994; 153:5810-5818. [PubMed: 7527450]

114. Schwab N, et al. Fatal PML associated with efalizumab therapy: insights into integrin aL $\beta 2$ in JC virus control. Neurology. 2012; 78:458-467. [PubMed: 22302546] 


\section{Key points}

- Memory T cells and their ability to generate an anamnestic response are critical for protective immunity, but contribute to allogeneic organ transplant rejection

- $\quad$ Allospecific memory can be generated through heterologous cross-reactivity and homeostatic proliferation, as well as through prior exposure to allogeneic antigens

- Inhibitors of calcineurin and mammalian target of rapamycin effectively, but non-specifically, impede memory T-cell responses

- Co-stimulation blockade inhibits T-cell responses to de novo alloantigen, but does not inhibit allospecific memory T-cell responses

- $\quad$ Several therapeutic agents that target molecules upregulated on memory $\mathrm{T}$ cells have been shown to synergize with co-stimulation blockade to mitigate the effects of memory $\mathrm{T}$ cells in organ transplantation

- Further investigation of memory T cells in transplantation will enhance the application of current immunosuppression therapies, as well as guide the development of novel agents to improve outcomes 
a

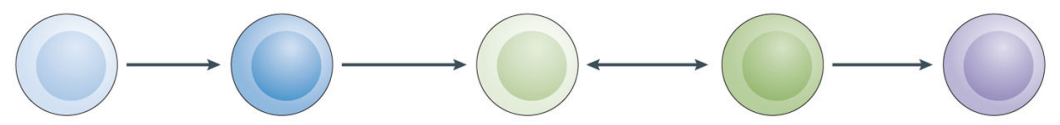

b
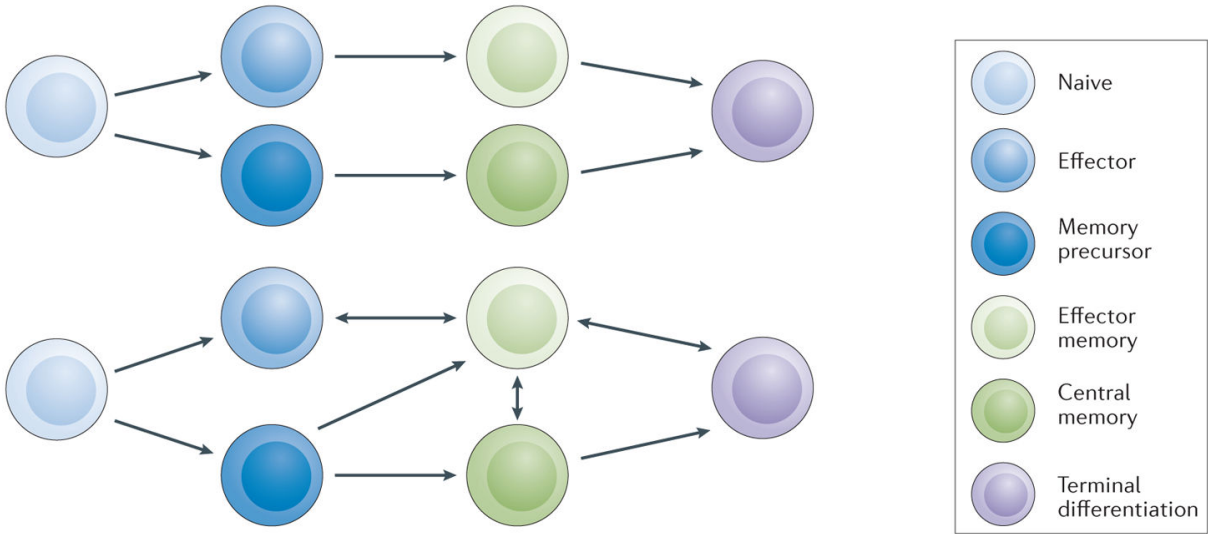

Figure 1. Plasticity of memory T cells

a | Sequential differentiation of $\mathrm{T}$ cells as a linear model of progression from naive to effector, then effector memory and central memory. $\mathbf{b} \mid$ Parallel differentiation occurs when an activated $\mathrm{T}$ cell divides to yield two distinct daughter cells with either effector or memory capabilities. $\mathbf{c} \mid$ Combined pathway of T-cell development and memory formation integrating models of parallel and sequential differentiation. 

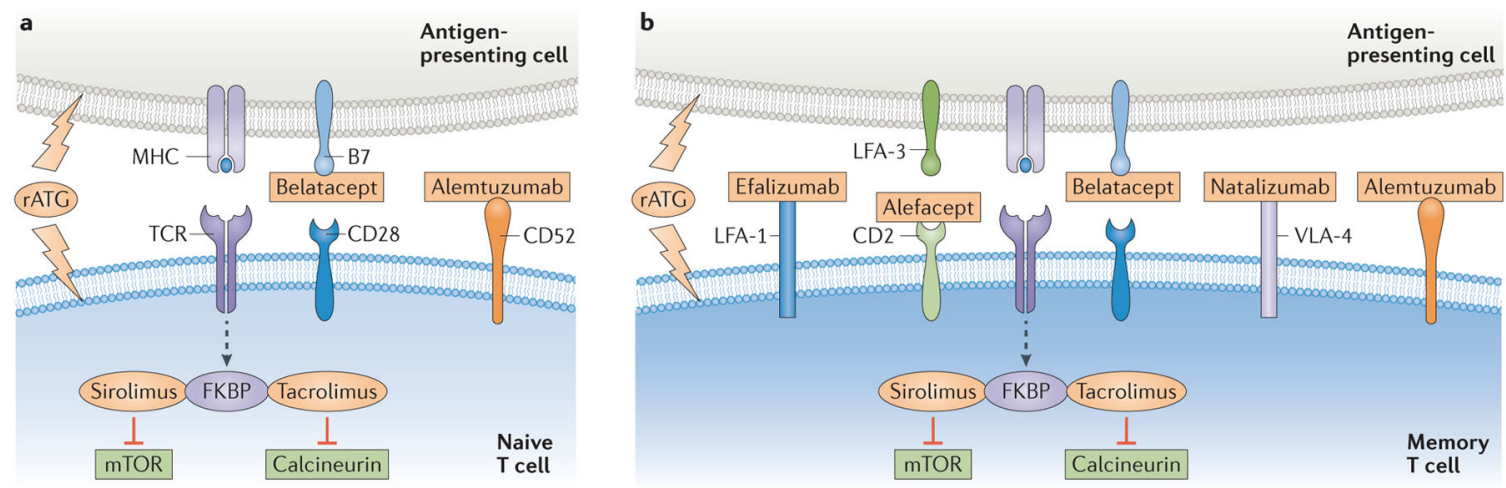

Figure 2. Immunosuppressive agents target molecules that are differentially expressed on naive and memory $T$ cells

a $\mid$ Naive T cells express high levels of CD28 and are susceptible to inhibition by belatacept. b | Memory T cells express low levels of co-stimulatory molecules but upregulate the coinhibitory molecule CD2 and adhesion molecules such as leukocyte function-associated antigen-1 (LFA-1) and very late antigen-4 (VLA-4). These molecules can also be specifically targeted: CD2 is inhibited by alefacept, LFA-1 is inhibited by efalizumab, and VLA-4 is inhibited by natalizumab. Both naive and memory T cells are susceptible to depletion using rabbit antithymocyte globulin (rATG) or alemtuzumab, which targets CD52. Calcineurin inhibitors (for example, tacrolimus) and mTOR inhibitors (for example, sirolimus) inhibit downstream cell signalling in naive and memory $\mathrm{T}$ cells during T-cell activation and thus prevent T-cell responses. FKBP, FK506-binding protein; TCR, T-cell receptor. 